\title{
Language Shift and Ethnic Identity: Focus on Malaysian Sindhis
}

\author{
Maya Khemlani David, Ph.D. \\ University of Malaya Asia-Europe Institute Kuala Lumpur, Malaysia \\ Chartered Institute of Linguistics, London, United Kingdom \\ Liaquat A. Channa, Ph.D. \\ Associate Professor, Department of English, \\ Balochistan University of I.T, Engineering \& Management Sciences (BUITEMS), \\ Quetta, Balochistan, Pakistan \\ Syed Abdul Manan, Ph.D. \\ Associate Professor, Graduate School of Education \\ Nazarbayev University, Nursultan (Astana), Kazakhstan \\ Francisco Perlas Dumanig, Ph.D. \\ Assistant Professor, Department of English \\ University of Hawaii at Hilo \\ Hawaii, USA
}

\begin{abstract}
This paper focusses on the minority community of the Malaysian Sindhis to show that ethnic and cultural identities can be constructed through means other practices than solely by the heritage languages. The study draws on an open-ended question directed to 79 lady members of the Sindhi community in Kuala Lumpur, Malaysia. The respondents were women aged 50-70 and a friend of a friend helped in obtaining further respondents. This age group was selected as they often met for kitty parties, gambling sessions and lunch parties. Their one-word responses were recorded and returned to the facilitator helping in data collection. The question was "What do you mean when you say you are a Sindhi?". Based on the data, we contend that the term ethnicity denotes a subjective sense of community, meaning a shared identity which results in a sense of group solidarity. Identity is rooted in actual cultural practices and experiences.
\end{abstract}

Key words: $\quad$ LANGUAGE SHIFT; ETHNIC IDENTITY; MALAYSIAN SINDHIS; COMMUNITY OF PRACTICE

\section{Introduction}

The link between language and ethnicity is highly contested. A number of writers such as Bucholtz and Hall (1995) are of the view that the ideological link between language and ethnicity is potent. Similarly, Schmidt (2008) focused on the link between language and ethnicity and stated that "language plays a crucial role in the self-identification of an ethnic group" (p. 2). In fact, as early as 1998, Fishman (1998) stated categorically that "at every stage, ethnicity is linked to language" (p. 5). But is language salient to ethnicity? It has been observed that in cases where the heritage language is being lost the strong tie between language and ethnicity is also lost (see Zentella, 1997). Reyes (2010) emphasized that "there is no one-to-one correspondence between language and ethnicity" (p. 420). In other words, language does not constitute the sole determinant of ethnicity.

Grin (2003), however, took the position that ethnicity was two-tiered and defined one tier as subjective (common ancestry and mother tongue) and the other self-assigned (by themselves and others). In fact, Castles and Miller (1998) argued that minorities can define themselves. Self-definition 


\section{Yinternational Research Journal}

p-ISSN 2202-2821 e-ISSN 1839-6518 (Australian ISSN Agency)

refers to the consciousness of group members of belonging together based on shared cultural and social values. In the same vein, Anderson (1991) understood the ethnic community as a group which has socially been constructed through means of a subjective belief of its members that they are indeed members of the said community. A community of practices is central in the process of ethnic construction. Identity as a member of an ethnic community is constantly performedperformativity - and is multifaceted. It depends on who one is interacting with, and with what objective in mind.

It is clear that apart from a common language, ethnicity can be viewed as a term that denotes a subjective sense of community meaning, a shared identity based on a common descent which results in a sense of group solidarity (Clammer, 2002). According to Barth (1969), an ethnic group shares fundamental cultural value, makes up a field of communication and interaction, and has a membership which identifies itself and is identified by others as constituting a category distinguishable from other categories.

As ethnicity is a socially constructed category, it, therefore, depends on the speech community being investigated (Clammer, 2002). Where for some communities, language constitutes their sense of identity as a member of a specific speech community, while for others language per se does not constitute their ethnic identity. Sarwani (2012), in an undergraduate paper on the Sindhi diaspora in Valencia, stated the community did not see the loss of the language as a reason for the loss of culture or as damaging to their ethnic identity. The core values of ethnic identity for the Sindhis in Valencia were food, religion, meeting with friends, celebrations, acknowledgment of their roots and their surnames. In this study, the focus was on the Sindhi community who lived in Malaysia.

In many studies, ethnic identities that migrants construct for themselves draw upon comparisons with other groups or communities. Verkuyten (1997), for example, showed that Turkish inhabitants in Rotterdam when discussing issues of ethnic identity drew upon many different comparisons between themselves, Dutch nationals, and other groups. Focusing on the Sindhis, Banarsidass (2007) viewed that the Sindhis are a very ambitious, highly motivated and achievement-oriented society; they help one another and compete with one another. He explained that the Sindhi diaspora is a trade diaspora and trade is their religion, their way of life. Thapan (2002), who discussed the Bhaiband (merchant) Sindhis, said that they conspicuously spent the money that they earned in order to feel successful. They "offered lavish entertainment to members of the community on marriage, a wedding anniversary" (p. 40).
Vol. 10 No. 012020

82801001202001

The representation by others of the Sindhi community is not the focus of this study. Nor is the representation of the Sindhis of other communities. The emphasis in this study is on their self-representation of themselves as Sindhis. Outsiders (other Malaysians) categorize them as Indians. But how do they categorize themselves? Such categorizations come from attitudes. Attitudes have a cognitive component in that they represent beliefs and have an evaluative dimension. They also have a behavioral component in that they are taken to cause behavior (Loersch, Brandon, and Petty 2007, Pajares 1992). In this research, we will discuss both the beliefs and behaviors of the Sindhis as members of the community as they themselves perceive it.

In some communities, speaking a common language makes them members of a particular ethnic group. But what is the case when a heritage language is dying due to language shift? Identities and a sense of community can be constructed not only through ethnic language use but also through other variables. The objective of this research is to determine what in the cognition of English speaking Malaysian Sindhis constitute their Sindhi identity.

Motivated by the above discussion, we wanted to understand the following questions. How do the Sindhis in Malaysia construct their identity? What role does language play in the construction of ethnic identity for Sindhis? How does a Sindhi enact an identity as a Sindhi? Identities as a member of an ethnic group are models in people's minds and manifest themselves in particular ways of behaving. What are the models, norms or group attributes deemed appropriate to group membership for this community?

\section{The Sindhis}

Sindhi Hindus are a diasporic community. Prior to the partitioning of the Indian subcontinent, many of the Sindhi Bhaiband or trading communities had ventured to different parts of the world. However, with the partitioning of the Indian sub-continent in 1947, they had to flee to India, Malaysia, Singapore, Japan, Hong Kong and many other countries where they have now settled (Kumar, 2012).

The Malaysian Sindhi community, like many other Sindhi Hindu communities in the diaspora (see Thapan, 2002; David, 1998; 1999), have shifted away from the habitual use of their heritage language. The home domain is not maintenance prone. Language has been deemed to play an important role in ethnic identity ascription. If language is not the raison d'etre for the community what then, in their perception, constitutes Sindhiness?

The Sindhi community in Malaysia is very small - about 700 strong as against a population of about 33 million (David, 


\section{Yinternational Research Journa}

p-ISSN 2202-2821 e-ISSN 1839-6518 (Australian ISSN Agency)

1998; 1999). Though small, there are close and dense networks; members of the community are constantly interacting with each other (see David, 1998; 1999). In the past, first-generation Sindhis owned shops or businesses and even houses (generally shop houses) in the same areas, for example, Bishop Street in Penang and Batu Road (now Jalan Tuanku Abdul Rahman) in Kuala Lumpur. Many of the Malaysian Sindhis are related through blood ties or marriage.

Most Sindhis have surnames that end with the suffix "ani" which means 'belonging to' (Thapan 2002 p. 15). In Malaysia, there is much interaction among members of the community. They meet often for social and religious occasions. Women meet to play cards. Couples meet for dinners. Members of the community are invited for weddings, birthday parties, chati or baptism ceremonies and many other social and religious functions. They meet for religious ceremonies like Satsung, Gayathri Mantra, and for many Malaysian Sindhis, the symbol of Sindhi religious identity is Jhulelal. Even the Sindhis who have converted to Christianity and the nominal few who are Muslims due to marriages with Muslims interact easily with the dominant Sindhi Hindus.

The Sindhi Association of Malaysia (SAM) holds regular monthly religious functions to celebrate Chand or the full moon. SAM also organises a number of social and cultural functions throughout the year. In short, though small there are close and dense networks and members of the community are constantly interacting with each other. Inevitably, they know very quickly if there are problems between mothers and daughters-in-law, break-ups in marriages, illness and deaths in families, etc.

There is a strong sense of community not only within the country but with Sindhis in different parts of the world. Malaysian Sindhis have relatives not only within the country but also in many parts of the world. Daughters are given in arranged marriages to young men living in Chile, Vancouver, London, Singapore, Jakarta, Japan, St Maarten etc. Daughters come home to Malaysia and parents visit their daughters in their new homes in Canada, America, India, Philippines, etc. Sons too also contract arranged marriages with Sindhi women who come from different parts of the world like Indonesia, Singapore, and Pakistan etc. In this way, Sindhi networks across the globe are built.

In addition to local ethnic-based associations like the Sindhi Association of Malaysia (SAM), there is an International Sindhi Sammelan or gathering where Sindhis from around the world gather annually in a specific geographical locality to spend time together. In 2019 for instance, they met in Barcelona for a cruise. Such interactions between global
Vol. 10 No. 012020

82801001202001

Sindhis provide an opportunity for both trading alliances and for selection of potential brides or bridegrooms.

\section{Methodology}

How do members of the mainly English-speaking Sindhi community construct their ethnic identity? The term social representations (Moscovici, 2000) have a prescriptive dimension in that a society's social representations constitute norms for thinking and behaviour of a community. A question was directed to 79 lady members of the Sindhi community in Kuala Lumpur, Malaysia. The respondents were women aged 50-70 and a friend of a friend helped in obtaining further respondents. This age group was selected as they often met for kitty parties, gambling sessions and lunch parties. Due to the social ties and constant interaction among members of the community, it was fairly easy to get the cooperation of one member in each of these groups to ask the others when they met this question. Their one-word responses were recorded and returned to the facilitator helping in data collection. The question was "What do you mean when you say you are a Sindhi?". They were asked to give the first descriptor that came to mind. The response to this question was recorded and the themes which emerged as a result of this are discussed.

In addition to the question directed at members of the community, the first author's three-year ethnographic study of the community provided additional insights to what makes for a sense of being a member of an ethnic community. The first author attended social and religious gatherings in homes, hotels and temples. Both an emic and etic views of the community are thus obtained.

Coding and grouping of codes helped in identifying themes to determine commonalities of their collective self-concept as Sindhis which emerged when responses to the research question were collated and analysed. The themes that emerged are discussed in the findings. In addition, the field notes arising from the observations made up the data. These are now discussed.

\section{Results}

Only three of the respondents mentioned language and three mentioned lack of a homeland. Only one mentioned the use of Ani in their surname as a distinguishing feature of ethnicity. Focusing on characteristics of the community, 17 said they were hospitable, friendly, loving and caring, fun-loving. They get along with each other and help each other. Six said they saw themselves as survivors and had a high level of tolerance. Twelve said they were an enterprising and hardworking business-minded community while 5 said they were professionals with a high IQ. Eight mentioned they were good-looking people who enjoyed good things in life like 


\section{Yinternational Research Journal}

p-ISSN 2202-2821 e-ISSN 1839-6518 (Australian ISSN Agency)

diamonds, expensive clothes and rich food. Sindhi cuisine was a marker of their ethnic identity for 9. Another 6 said they were God-fearing and celebrated religious ceremonies like Thadri and Safari. Another 6 said that they had a rich culture. Only 3 mentioned negative qualities like the love of gambling and gossip. Gossip is a means of establishing social solidarity, e.g., who is divorcing, who is getting married, who is in hospital. In a way, gossip shows knowledge and cohesion about other community members.

\section{Ethnographic study and Field Notes}

They are bound together by family, social and working relationships. Their close and dense networks, kinship and work-related ties, their shared interests in business and their celebrations of both social and religious occasions especially the celebration of Cheti Chand, the Sindhi New Year led to close and constant interactions among members of the community. For instance, a Malaysian Sindhi who is married to an Indian Sindhi and has lived in India for 30 years said, "Interesting one time on my visit to Kuala Lumpur, I was invited to a kitty party and asked to show the jewelry that I sell." Another lady who was also studied in Kuala Lumpur but married to a Sindhi in Delhi said, "Only I would like to add that the way a lot of them dress with solitaire diamonds and boast about their latest jewelry purchases, also identifies them as Sindhis." Social and trading relationships are maintained through these ways too.

Even the religious identity which tends to bind communities who have shifted away from their mother tongue is not really a substantial binding factor. This is because even within the Hindu religion some are Sai Baba devotees, others Krishna devotees, others Radha Swami Adherents and others are ISKCON (Hare Krishna) believers. In Malaysia, there are some Sindhi Christians and few Sindhi Muslims. It was noted that notwithstanding religious differences the Malaysian Sindhis interacted easily with each other. In fact, Sindhi Muslim guests from Pakistan who came to Malaysia were invited to share their songs and dances with Malaysian Sindhis. The common binding factor was the fact that they were Sindhis and they and their ancestors belonged to the same land and shared the culture of the land.

Overarching religion ethnicity is a common binding factor. Regardless of religious faith, the Sindhis tend to meet regularly and socialize often whether it is for kitty parties, tea parties, to see movies, play cards, etc. Even those who have converted to Christianity retain their Indian names. This commonality binds them and brings them together whether in the temple, the gurdwara, the church. Recently, I attended a memorial service in a North Indian temple in Kuala Lumpur for a Sindhi who had been killed in an air incident. Attendees
Vol. 10 No. 012020

82801001202001

in the Hindu temple included many Sindhis who had varying religious beliefs. The eulogy was given in English by a fellow Sindhi. In another incident where the Akhand path ceremony took place in a gurdwara (there is for the Sindhis syncretism between Sikhism and Hinduism) for a Sindhi, the eulogy given by his daughter to a dominant Sindhi congregation was in English. At the dinner which followed the religious ceremony, I heard a 70 year- old Sindhi Christian woman discussing some verses from the Bible with another 70-yearold Sindhi man who compared it with what was said in the Ramanaya. The entire discussion was in English.

What are the norms or group attributes deemed appropriate to group membership? Ethnic identity is implicated in social actions and relationships with others. For instance, bending and touching the feet of older community members is considered as a sign of respect among the Sindhis all over the world. The Sindhis tend mainly to socialize among themselves. In Kuala Lumpur, whether it is a birth, a wedding, illness or death, the community jells together and gives support to each other. Recently, when a woman lost her spouse due to old age, the children requested community members to rally round and often invite the grieving wife for lunch.

While members of the first generation shared partition experiences (when the Indian subcontinent was divided) and on arriving in new countries they helped each other with their respective businesses, members of the second generation also meet often socially. Moreover, the second or third generation does not speak the language or understand the language. But, Sindhi food is cooked every day at home or if even seldom in case of overseas families, they crave for that. Thus, they identify themselves as Sindhis with food besides the loss of language.

It is not only the Sindhi community in Kuala Lumpur that jells together. Once a Sindhi writer came from India and wanted to do a reading of her latest book. She wrote to the Sindhi Association of Malaysia who warmly welcomed her and organized an event where the book could be launched. In addition, there are ways in which relationships are developed on Social media too. For example, a member of the community sent to the first author of this article a message asking her if she wanted books on the Sindhis once the member found out her interest. Another asked the first author if she wanted to join a Wednesday Group of 10 ladies who met once in two months for lunch in different restaurants. Malaysian Sindhi women who have married partners who live in different countries maintain their ties with members of the community through Facebook and WhatsApp. So, social media has helped to maintain these ties. Many Sindhi 


\section{Yinternational Research Journal}

p-ISSN 2202-2821 e-ISSN 1839-6518 (Australian ISSN Agency)

Associations exist nowadays in different countries of the world and Sindhis connect with the networks when visiting these countries. When the first author of this study conducted a study of the Sindhis in London, she met professionals through the UK Sindhi Facebook. In addition, a Sindhi friend in Kuala Lumpur said her sister was in London and I could meet her for help.

Once a pure trading community, many members of the second and third generation is now professionals and there is high upward mobility. In short, there is much interaction among members of the community. They meet often for social and religious occasions. A number of women tend to meet daily to play cards and couples meet for dinners. All members of the community are invited for Sindhi weddings, chati or baptism ceremonies, and religious ceremonies like satsung gayathri mantra etc.

\section{Discussion}

Language has been deemed to play an important role in ethnic identity ascription. Only three respondents mentioned language as constituting their Sindhi identity.

According to Castles and Miller (1998), minorities can selfdefine themselves. Self-definition refers to the consciousness of group members of belonging together based on shared cultural and social values. Membership of a group can be associated with a sense of self. The respondents ascribed to themselves many positive features. These focused on characteristics of the community like being hospitable, sociable, charitable, enjoying ethnic dishes, and a good life. They are conscious of their inherent business ability. Language per se did not constitute their ethnic identity.

As the data suggest, ethnic identity formation revolves around the characteristics such as trade, food, networking and socializing, and reaching out and helping. Thus, the social construction of Sindhi ethnicity is based upon practicing the cultural values that they as generations have been doing despite not being able to speak or communicate in Sindhi. Here, interestingly, Sindhiness essentially goes beyond the confines of identifying themselves with Sindhi language or any specific religious belief. Although culture is a highly complex and multi-layered phenomenon due to the forces of globalization and glocalization, particularly for the minorities such as this Malaysian Sindhi community, data exhibit that the Sindhi minority does try to stick with and keep alive their values that they inherited from their ancestors. It must be emphasized that there is a strong sense of community not only within Sindhis in Malaysia but there is a close connection between Malaysian Sindhis with Sindhis in different parts of the world. These ties encompass both kinship and trading ties.
Vol. 10 No. 012020

82801001202001

\section{Conclusion}

Ethnicity is a term that denotes a subjective sense of community, meaning a shared identity which results in a sense of group solidarity. Identity is rooted in the actual cultural experience. Identities are tied up in details and everyday practice. Cultural identities are constructed through means other than heritage languages. The salience of language and ethnicity are not dependent on each other for Malaysian Sindhis. Others focused on characteristics of the community such as being hospitable, sociable, charitable, enjoying ethnic dishes, and a good life. Language per se did not constitute their ethnic identity. The concept of identity formation used in this paper combines contributions from both social psychology and post-structuralism, where identity is seen as the way individuals see themselves. If ethnicity is socially constructed then members of the Malaysian Sindhi community have identified themselves not as traditionally done by language but by characteristics of the community. Their social life is mainly confined to the community that stresses the cultural values. Traditions in culture and cooking are maintained but not the language. Overall, identity in this study seems to be rooted in the actual cultural experience.

\section{References}

[1]. Anderson, B. (1991). "IMAGINED COMMUNITIES: REFLECTIONS ON THE ORIGIN AND SPREAD OF NATIONALISM." London: Verso.

[2]. Barth, F. G. (1969). "ETHNIC GROUPS AND BOUNDARIES: THE SOCIAL ORGANIZATION OF CULTURE DIFFERENCE". Bergen: Universiters forlaget.

[3]. Bucholtz, M., \& Hall, K. (Eds.). (1995). "GENDER ARTICULATED: LANGUAGE AND THE SOCIALLY CONSTRUCTED SELF”. New York: Routledge.

[4]. Castles, S.. \& Miller, M. J. (1998). "THE AGE OF MIGRATION: INTERNATIONAL POPULAR MOVEMENTS IN THE MODERN WORLD." New York: Guilford Press.

[5]. Clammer, J. R. (2002). "DIASPORA AND IDENTITY: THE SOCIOLOGY OF CULTURE IN SOUTHEAST ASIA." Malaysia: Pelanduk Publications.

[6]. David, M. K. (1999). "LANGUAGE SHIFT AMONGST THE SINDHIS OF MALAYSIA." South Pacific Journal of Psychology, 10(1),61-67.

[7]. David, M., \& Dumanig, F. P. (2011). Social Capital and Politeness Strategies in Fostering Ethnic Relations in Malaysia and the Philippines. IARS' 
International Research Journal, 1(1). Retrieved from https://researth.iars.info/index.php/curie/article/view $\underline{13}$

[8]. David, M., Dealwis, C., \& Shanmuganathan, T. (2015). The Punjabi Sikh Community in Kuching: Assimilation or Enculturation?. IARS' International Research Journal, 5(1). Retrieved from https://researth.iars.info/index.php/curie/article/view $\underline{143}$

[9]. David, M.K. (1998). "LANGUAGE SHIFT, CULTURAL MAINTENANCE, AND ETHNIC IDENTITY; A STUDY OF A MINORITY COMMUNITY: THE SINDHIS OF MALAYSIA." International Journal of the Sociology of Language, 130(1). DOI: 10.1515/ijsl.1998.130.67.

[10]. Fishman, J. A. (1998). "THE NEW LINGUISTIC ORDER. FOREIGN POLICY”, (113), 26. DOI: $10.2307 / 1149230$.

[11]. Grin, F. (2003). "DIVERSITY AS PARADIGM, ANALYTICAL DEVICE, AND POLICY GOAL". In Kymlicka and Patten (Ed.), Language rights and political theory (pp. 169-188). Oxford: Oxford University Press. Retrieved from https://archiveouverte.unige.ch/unige:40383.

[12]. Kumar, M. S. (2012). “ALTERNATIVE ENGAGEMENTS WITH THE 'HOMELAND': SIND AS AN EXPRESSION OF DIASPORIC SINDHI IDENTITY”. ISA eSymposium Sociology, pp. 1-10

[13]. Loersch, C., Kopp, B., and Petty, R. E. (2007). “ATTITUDE CHANGE”. In R. F. Baumeister and K. D. Vohs (Eds.). Encyclopedia of Social Psychology (pp. 62-66). Thousand Oaks: SAGE.

[14]. Meng, N. Y., Hei, K. C., \& David, M. K. (2011). Discourse, Politeness and Ethnic Sensitivities in Malaysian Parliament. IARS' International Research Journal, 1(2). Retrieved from https://researth.iars.info/index.php/curie/article/view 19

[15]. Moscovici, S. (2000) "SOCIAL REPRESENTATIONS: EXPLORATIONS IN SOCIAL PSYCHOLOGY." Cambridge, UK: Polity Press.

[16]. Pajares, M. F. (1992). "BELIEFS AND EDUCATIONAL RESEARCH: CLEANING UP A MESSY CONSTRUCT." Review of Educational Research, 62(2), 307-332.

[17]. Reyes, A. (2010). "LANGUAGE AND ETHNICITY”. In N. H. Hornberger \& S. L. McKay (Eds.). Sociolinguistics and Language Education (pp. 398-426). Bristol, UK: Multilingual Matters.
[18]. Sarwani, K.C. (2012). "HOW HAS A SENSE OF IDENTITY BEEN CREATED BY THE SINDHI DIASPORA IN VALENCIA?". University of Sussex

[19]. Schmidt, U. (2008). "LANGUAGE LOSS AND THE ETHNIC IDENTITY OF MINORITIES. ECMI" Brief \# 18, Flensburg: European Center for Minority Issues.

[20]. Thapan, A. (2002). "SINDHI DIASPORA IN MANILA, HONG KONG AND JAKARTA. MANILA": Ateneo de Manila University Press.

[21]. Verkuyten, M. (1997). "DISCOURSES OF ETHNIC MINORITY IDENTITY”. British Journal of Social Psychology, 36(4), 565-586. DOI: 10.1111/j.2044-8309.1997.tb01150.x

[22]. Zantella, A. C. (1997). "GROWING UP BILINGUAL”. Malden: Blackwell Publishing. 